Rodante A. Roldan, MD',

Erasmo Gonzalo DV Llanes, MD 2,3,

Romeo L. Villarta MD, MPH ${ }^{2,3}$

'Department of Otorhinolaryngology

Philippine General Hospital

University of the Philippines Manila

2Department of Otorhinolaryngology

College of Medicine - Philippine General Hospital

University of the Philippines Manila

${ }^{3}$ Department of Otolaryngology Head and Neck Surgery Quirino Memorial Medical Center

\section{Embryonal Rhabdomyosarcoma of the Mandible}

\section{ABSTRACT}

Objectives: 1] To describe a case of an embryonal rhabdomyosarcoma presenting as a radiolucent mandibular mass in a 3-year-old child. 2] To review existing literature on the clinical picture and pathophysiology of intraosseous rhabdomyosarcoma. 3] To identify learning points in the diagnosis of intraosseous rhabdomyosarcoma.

\section{Design: Case report.}

Setting: A tertiary referral hospital.

\section{Patients: One (1)}

Results: A case of a 3-year-old child with a radiolucent mandibular mass is described. The final histopathologic report turned out to be embryonal rhabdomyosarcoma. Intraosseous rhabdomyosarcomas are rare occurrences (3.5\% in one review), and clinically present in younger age groups, with a non-tender, enlarging, firm-hard mass over a specific area. A review of the available literature on intraosseous rhabdomyosarcomas, and its proposed pathogenesis, is presented.

Conclusion: A case of a radiolucent mandibular mass in a 3-year-old child is presented. Intraosseous rhabdomyosarcomas of the mandible are rare occurrences that pose challenges to the otorhinolaryngologist. Taken separately, the presentation, patient characteristics, clinical course, ancillary laboratories and imaging modalities may lead even the most astute otorhinolaryngologist astray. The whole clinical picture should be taken together so that the correct diagnosis will not be missed despite the rare presentation.

Keywords: embryonal rhabdomyosarcoma, intraosseous rhabdomyosarcoma, mandibular mass

TUMORS of the head and neck can be grouped according to their site of origin, histologic type, or whether they are benign or malignant. Appropriate management protocols for these tumors parallel such groupings, favoring medical or surgical, conservative or aggressive approaches, with varying gradations in between.

We describe a rare site of occurrence of a common childhood malignancy together with the concomitant difficulties inherent in making decisions in situations with few or no precedents.

\section{CASE REPORT}

A 3-year-old male from Caloocan City was observed by his parents to have a hard, nonpainful, non-movable $1 \times 1 \mathrm{~cm}$ right mandibular mass four months before admission. There were no other symptoms of fever, cough, colds, trismus, or malocclusion.

The mass progressively enlarged to $7 \times 5 \mathrm{cms}$, resulting in gross facial asymmetry with no skin involvement. Intra-orally, it extended into the gingivobuccal gutter and floor of the mouth. There 


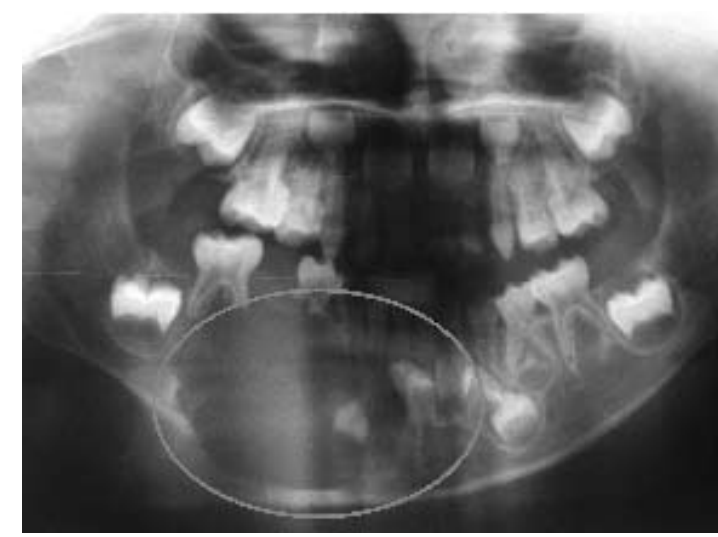

Figure 1. Panoramic radiograph showing unilocular cystic mass. Note scalloping of the mandible at cyst borders.

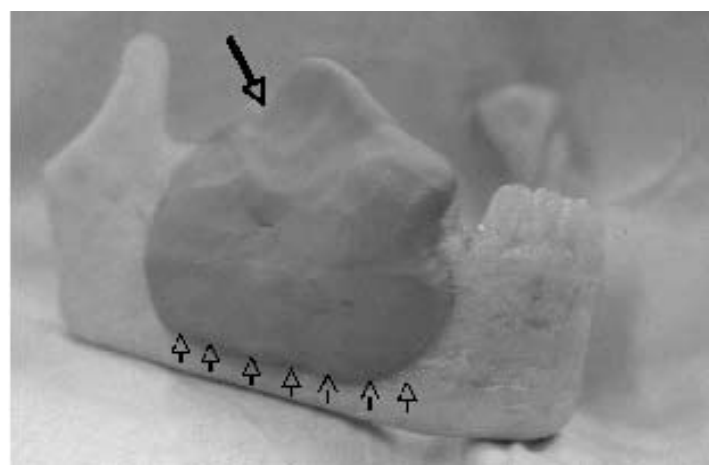

Figure 2. A clay model showing the tumor in situ.

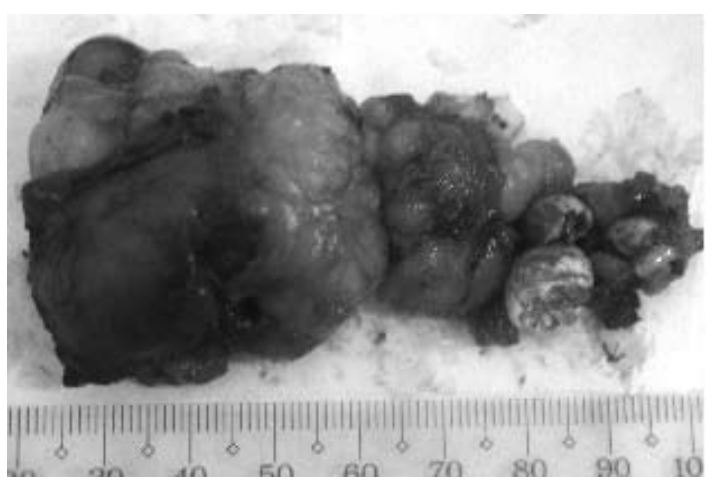

Figure 3. Gross specimen measuring $7.5 \times 4.5 \times 2 \mathrm{~cm}$. were no carious teeth, and the overlying dentition was non-mobile and undisplaced. At this time, a $2 \times 3 \mathrm{~cm}$ firm, irregularly shaped, non-tender, slightly movable mass in the submental area was also noted.

A panoramic radiograph revealed a unilocular radiolucent cystic mass, associated with an unerupted tooth and the roots of the first and second premolars on the right, extending from the para-symphyseal area to the second premolar on the right. Scalloping of the mandible at the cyst borders was also noted (Figure 1). The patient was admitted for an excisional biopsy with the primary impression of an Odontogenic Tumor.

The mass was exposed via a gingival incision through the dental papilla and a mucoperiosteal rhomboid flap. It measured $7.5 \times 4.5 \times$ $2 \mathrm{cms}$, with a thick fibrous capsule. There were no cystic areas, and no evidence of bony erosion (Figure 2).

En bloc excision with removal of the first and second right mandibular premolars and the embedded unerupted tooth was performed, leaving a thin rim of mandible intact. The firm, nodular submental mass with cream, white, and tan areas was excised transorally superior to the mylohyoid muscle.

Antibiotic-impregnated gauze was packed into the defect, and removed after six days when the alveolar-mucosal defect was closed under general anesthesia.

Final histopathologic report was Embryonal Rhabdomyosarcoma for both mandibular and submental masses. The patient was referred to the Pediatric Hematology-Oncology and the Radiation-Oncology Services for further management.

\section{DISCUSSION}

Rhabdomyosarcomas are the most common sarcomas in children, accounting for $4-8 \%$ of all malignant lesions in those younger than 15 years of age 1 . Of the four principal histologic types (embryonal, alveolar, pleomorphic, and botyroid), embryonal rhabdomyosarcoma is the most common and occurs mainly in children younger than 12 years of age. Slightly more boys than girls are affected, with the incidence higher in Caucasians than in Black or Asian children ${ }^{1,2}$.

The clinical presentation varies with the anatomic site 1,2 , usually presenting in less than a year as a painless, rapidly growing mass.

Histologically, rhabdomyosarcomas arise from precursors of striated muscle. Appearances vary, ranging from primitive-appearing lesions with virtually no evidence of muscle differentiation, to those containing numerous strap-shaded cells with cross-striations ${ }^{1}$.

Genetically, there is loss of heterozygosity at the $11 \mathrm{p} 15.5$ locus, and loss of maternal with duplication of paternal-chromosomal material ${ }^{3,4}$. They are most commonly seen in the head and neck (38\%), urogenital (21\%), extremities (18\%), trunk (7\%), and retroperitoneum (7\%)'. In nonparameningeal head and neck sites, primary tumors involve the orbit, pharynx, and soft tissues of the head and neck, in decreasing order of frequency ${ }^{1}$.

In a 23-year review of 11,250 head and neck cancer cases by Gorsky, there were 139 cases (1.24\%) of sarcoma; and of these, there were only 16 cases $(0.14 \%)$ of intra-oral soft tissue sarcoma ${ }^{6}$. Dito and Batsakis found only 6 out of 170 cases (3.5\%) of rhabdomyosarcoma occurring in 


\section{CASE REPORTS}

the mandible 7 . A review of 16 cases by Bras et al, reported an embryonal rhabdomyosarcoma involving the jaw ${ }^{7}$.

A similar case of an intra-osseous rhabdomyosarcoma of the mandible was reported by Loducca et al in Sao Paulo, Brazil5. Table 1 shows the similarities and differences between Loducca's patient and ours.

Both cases belonged in the pre-school age group, exhibited symptoms for less than 1 year, appeared primarily as a bony lesion involving the body of the right hemi-mandible, had similar embryonal type rhabdomyosarcomas, but different radiographic appearances ("moth-eaten" versus unicystic with scalloped borders).

How do rhabdomyosarcomas, which by definition arise from striated muscle, occur in bone? The histogenesis of this tumor may support its development in areas in which striated muscle is absent. Rhabdomyosarcomas are thought to arise from stores of undifferentiated mesenchyme with the potential for rhabdomyoblastic differentiation. It may also arise from embryonal muscle tissue that was trapped during the early phases of tissue development. The molecular pathways involved in the pathogenesis of rhabdomyosarcoma are still being investigated. Preliminary studies suggest that mutations may upset the balance between proliferation and differentiation of primitive mesenchymal tissue in the subverted myogenesis and development of rhabdomyosarcoma ${ }^{5}$. Embryonal rhabdomyosarcoma may also undergo inactivation of one or more tumor suppressor genes as shown by the loss of heterozygosity for multiple closely linked foci at chromosome $11 \mathrm{p} 15.5^{3,4}$.

Our experience suggests that not all radiolucent mandibular tumors associated with an unerupted tooth are odontogenic. More aggressive disease may exist despite scalloped tumor borders on radiographs, especially with the presence of nodal involvement. With the paucity of data on a standard or classic radiographic appearance of intraosseous rhabdomyosarcomas, the diagnosis may be missed if the patient and his disease are not considered as a whole.

\section{REFERENCES:}

1. Thawley SE, et al.: Dental and jaw tumors. Comprehensive management of head and neck tumors. 2nd edition. WB Saunders. 1999. USA.

2 Arndt CA, Crist WM: Common musculoskeletal tumors of childhood and adolescence. N Engl J Med 1999 Jul 29; 341(5): 342-52

3 Merlino G, Helman LJ: Rhabdomyosarcoma--working out the pathways. Oncogene 1999 Sep 20; 18(38): 5340-8.

4 Barr FG: Molecular genetics and pathogenesis of rhabdomyosarcoma. J Pediatr Hematol Oncol 1997 Nov-Dec; 19(6): 483-91.

5 Loducca SV, et al.: Intraosseous rhabdomyosarcoma of the mandible: a case report. Int J Surg Pathol 2003 Jan;11(1):57-60.

6 Gorsky M, Epstein JB: Head and neck intra-oral soft tissue sarcomas. Oral Oncol 1998; 34:292296.

7 Sekhar MS, et al.: Alveolar rhabdomyosarcoma involving the jaws: a case report. J Oral Maxillofac Surg 2000; 58:1062-1065.

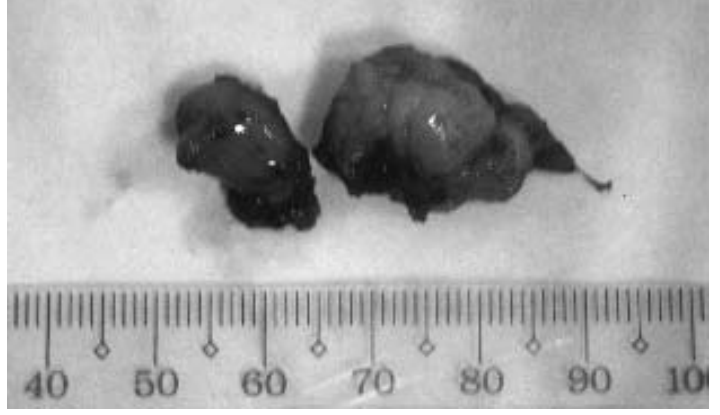

Figure 4. Gross appearance of the submental mass, 2 adjacent masses, measuring an aggregate diameter of 1.75 $\mathrm{x} 1.5 \times 1 \mathrm{~cm}$.

Table 1. Two Cases of Intraosseous Embryonal Rhabdomyosarcoma

\begin{tabular}{|c|c|c|}
\hline & Loducca et al & Roldan et al \\
\hline Patients & 6-year-old female & 3-year-old male \\
\hline Symptoms & $\begin{array}{l}\text { Painful mandibular swelling } \\
\text { with a rapid increase in size }\end{array}$ & $\begin{array}{l}\text { Hard, non-painful, non- } \\
\text { movable right mandibular } \\
\text { mass }\end{array}$ \\
\hline Duration of symptoms & 1-month & 4 months \\
\hline Physical Examination & $\begin{array}{l}\text { Gross facial asymmetry } \\
\text { with skin swelling, no } \\
\text { changes in skin color or } \\
\text { temperature } \\
\text { Painful, firm mass that } \\
\text { seemed to be intraosseous, } \\
\text { involving the right body of } \\
\text { the mandible, measuring } \\
\sim 30 \text { mm } \\
(+) \text { trismus } \\
(-) \text { oral mucosal } \\
\text { involvement }\end{array}$ & $\begin{array}{l}\text { Gross facial asymmetry with } \\
\text { skin swelling, no changes in } \\
\text { skin color or temperature } \\
\text { Non-painful mass on the } \\
\text { right body of the mandible, } \\
\text { extending into the } \\
\text { gingivobuccal gutter and } \\
\text { floor of mouth, measuring } \\
\sim 7 \times 5 \mathrm{cms} \\
(-) \text { trismus } \\
(-) \text { oral mucosal } \\
\text { involvement }\end{array}$ \\
\hline $\begin{array}{l}\text { Panoramic Radiograph } \\
\text { Findings }\end{array}$ & $\begin{array}{l}\text { Destruction of the body of } \\
\text { the mandible, with irregular } \\
\text { limits, and a "moth-eaten" } \\
\text { appearance }\end{array}$ & $\begin{array}{l}\text { Unicystic mass with } \\
\text { scalloped borders, extending } \\
\text { from the para-symphyseal } \\
\text { area to the second premolar } \\
\text { on the right }\end{array}$ \\
\hline Final Histopath & $\begin{array}{l}\text { Embryonal } \\
\text { Rhabdomyosarcoma }\end{array}$ & $\begin{array}{l}\text { Embryonal } \\
\text { Rhabdomyosarcoma }\end{array}$ \\
\hline
\end{tabular}

